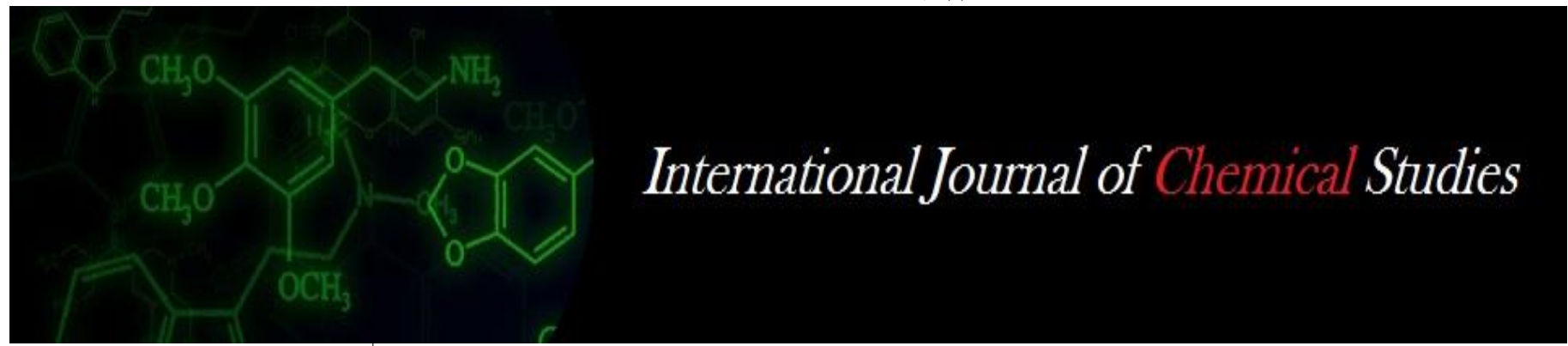

P-ISSN: 2349-8528

E-ISSN: 2321-4902

IJCS 2020; 8(1): 104-107

(C) 2020 IJCS

Received: 03-11-2019

Accepted: 04-12-2019

G Mahadevaswamy

Department of Plant Pathology,

PGI, Mahatma Phule Krishi

Vidyapeeth Rahuri, India

KS Raghuwanshi

Department of Plant Pathology,

PGI, Mahatma Phule Krishi

Vidyapeeth Rahuri, India

\section{SS Kulkarni}

Department of Plant Pathology, PGI, Mahatma Phule Krishi Vidyapeeth Rahuri, India
Corresponding Author:

G Mahadevaswamy

Department of Plant Pathology,

PGI, Mahatma Phule Krishi

Vidyapeeth Rahuri, India

\section{Performance of different germplasms of pomegranate against isolates of Alternaria alternata (Fr.) Keisler causing Blackspot on leaf and fruit of pomegranate}

\author{
G Mahadevaswamy, KS Raghuwanshi and SS Kulkarni
}

\begin{abstract}
Seven isolates of Alternaria alternata were recover from diseased leaves and morphologically characterized. Among 17 germplasms Mridula, Arakta, Kabuli, and Kabuli canoor were found were found highly susceptible with a PDI ranging between 53.33 to 66.67 per cent, nine germplasms includes KRS, P13, P23, Yarcaud local, Bhagwa, Shirin anar, Super bhagwa, Kabuli yellow, and Muscat new showed susceptible reaction, Jyoti GKVR, P16 and Muscat germplasms found to be moderately resistant reaction against isolate Aa361. KRS, Mridula, Yercaud local, Muscat and Shirin anar germplasms showed moderately resistant reaction against Aa2514 remaining were showed susceptible to highly susceptible reaction. Germplsms viz., Kabuli, Arakta, Kabuli canoor shows susceptible reaction and remaining all shows resistant to moderately resistant reaction against isolate Aa356. In response to isolate Aa2427 seven germplasms shows susceptible reaction and remaining were moderately resistant except Kasuri shows resistant reaction. In response to isolates Aa2523and Aa1726 many germplasms showed susceptible to highly susceptible reaction only few showed moderately resistant reaction. On isolate Aa1728 only Muscat germplasms showed resistant and remaining were susceptible to highly susceptipble.
\end{abstract}

Keywords: germplasms, pomegranate, Alternaria alternata (Fr.)

\section{Introduction}

Pomegranate (Punica granatum) is grown in tropical and subtropical regions of the world. The native range of pomegranate (Punica granatum L.) spans from Iran to the Himalayas in northern India, and this crop has been cultivated throughout the Mediterranean region since ancient times. Due to increasing evidence for health-promoting effects of pomegranate, the consumption of pomegranate fruit and juice has been increasing, as well as the amount of area dedicated to its cultivation.

At present, Maharashtra with an area of 136.75 thousand ha is the leading state in acreage and accounts for 68.7 per cent of the total area under pomegranate in the country. Other major pomegranate growing states are Karnataka (28.08 thousand ha) with production (328.92 thousand MT) having productivity of 11.71 MT per hectare (2016- 17). Gujarat is in third position 18.54 thousand ha cultivation of pomegranate with production of 278.10 thousand MT, having productivity of $15 \mathrm{MT}$ per ha and Andhra Pradesh (7.71 thousand ha). In recent years, pomegranate cultivation has also been started in Rajasthan, Orissa, Chhattisgarh, Uttarakhand and Madhya Pradesh at small scale (Anon, 2017) ${ }^{[1]}$.

The most popular varieties suitable for processing and table purposes are Ganesh, Mridula, Arakta, Bhagwa (Kesar), G-137 and Khandar in India. Though bacterial blight infection on pomegranate due to Xanthomonas axonopodis pv. punicae has attracted attention by researchers, growers and policy makers alike. Nevertheless, the infections due to fungal species which cause diseases such as anthracnose (Colletotrichum gloeosporioides), leaf spot and severe fruit spot/rot by Alternaria alternata, Cercospora spp., Drechslera spp. and Sphaceloma spp. etc. are more or less equally important and harmful in some orchards. Among these; severe spotting and fruit rotting due to Alternaria alternata; remainshitherto unexplored but potentially dangerous pathogen on pomegranate and considered tobe an emerging disease. Alternaria alternata (Fr.) Keissler is a ubiquitous necrotrophic fungus. 


\section{Materials and Methods}

Alternaria alternata was isolated from the infected leaves of pomegranate collected from Indian peninsular region. After performing their pathogen city test their culture was maintained on Potato dextrose agar medium at $27 \pm 1{ }^{\circ} \mathrm{C}$.

\section{Study the performance of different germplasm of Pomegranate against isolates of $A$. alternata}

Based on the morphology and molecular variability the isolates were made into seven groups. One virulent isolate were selected from each group for screening studies. Pomegranate cultivars maintained at the Arid zone, Department of Horticulture, MPKV Rahuri were screened for disease against A. alternata (Fr.) Keissler by artificial inoculation by using detached leaf technique (Yarwood, 1946) [11]

\section{Detached leaf technique}

Healthy leaves were collected from different pomegranate germplasms as detailed below. They were washed thoroughly with sterile distilled water and surface sterilized with $0.1 \%$ sodium hypochlorite by swabbing and again washed with sterile water to remove the traces of chemical. The pathogen inoculum was multiplied on potato dextrose agar media. A circular mycelial disc of $5 \mathrm{~mm}$ diameter was taken from the growing edge of the seven days old colony. The leaves were pin pricked at the centre to facilitate the entry of pathogen and the disc was placed such that the mycelia should face the upper surface of leaf. Inoculation is done only on the middle of the leaf leaflet. The inoculated leaflets were incubated in dark for $24 \mathrm{~h}$ at $\sim 22{ }^{\circ} \mathrm{C}$, and then maintained under cool white fluorescent diurnal light with a 12 hours photoperiod. The development of lesion was observed each day and finally disease severity was recorded on seventh day based on the area covered by the pathogen on the inoculated leaf using $0-5$ scale developed by Devananthan and Ramanujam (1995) ${ }^{[6]}$ :

Table 1: Rating scale

\begin{tabular}{|c|c|}
\hline Rating scale & \% Area infection \\
\hline 0 & No infection \\
\hline 1 & 1 to $25 \%$ necrotic leaf area \\
\hline 2 & 25 to $40 \%$ necrotic leaf area \\
\hline 3 & 41 to $60 \%$ necrotic leaf area \\
\hline 4 & 61 to $80 \%$ necrotic leaf area \\
\hline 5 & Above $80 \%$ necrotic leaf area \\
\hline
\end{tabular}

$$
\text { PDI }=\frac{\text { Sum of numerical rating }}{\text { Total number of leaf assesed }} \times \frac{100}{\text { Maximum disease rating }}
$$

They were grouped into five categories based on the PDI value (Mckinney, 1923) ${ }^{[7]}$ as:

Table 2: PDI value

\begin{tabular}{|c|c|}
\hline PDI & Reactions \\
\hline$<1 \%$ & Immune \\
\hline $1-10 \%$ & Highly resistant \\
\hline $10.1-25 \%$ & Resistant \\
\hline $25.1-40 \%$ & Moderately resistant \\
\hline $40.1-50 \%$ & Susceptible \\
\hline$>50 \%$ & Highly susceptible \\
\hline
\end{tabular}

\section{Results and Discussions}

Among the 17 pomegranate genotypes (Table 4.1) screened by artificial inoculations 7 isolates of $A$. alternata culture (Mycelial bit) under laboratory conditions using detached leaf technique (Yarwood, 1946) ${ }^{[11]}$. Representive isolates were selected based on molecular cluster formation; one isolate is selected from each cluster of different zones. It was revealed that many genotypes shows susceptible to highly susceptible reactions, meanwhile some of the genotypes also showed resistant to moderately resistant reactions.

Among 17 germplasms Mridula, Arakta, Kabuli, and Kabuli canoor were found were found to be highly susceptible with a PDI ranging between 53.33 to 66.67 per cent, nine germplasms includes KRS, P13, P23 Yarcaud local, Bhagwa, Shirin anar, Super bhagwa, Kabuli yellow, and Muscat new showed susceptible reaction, Jyoti GKVR, P16 and Muscat germplasms found to be moderately resistant reaction against isolate Aa361 (Table 4.2).

In response to the isolate Aa2514, among the germplasms Arakta, P23, Kabuli Yellow, Kabuli, Muscat New, Kasuri and Kabuli canoor showed highly susceptible reaction with PDI ranged from 53.33 to 66.67 per cent. The germplasms viz., Mridula, P13, P16, Bhagwa, Super bhagwa and Jyoti GKVR shows susceptible reaction with PDI 46.67 per cent. KRS, Shirin anar Yercaud local and Muscat shows moderately resistant reaction. On isolate Aa356 observed to be less virulent, maximum number of genotypes shows reistant to moderately resistant reaction, among them, the genotypes viz., KRS, Mridula, Yercaud local, Bhagwa, Jyoti GKVR, Kabuli Yellow, Muscat Muscat new and Kabuli were moderately resistant. Only Arakta are susceptible and remaining others are resistant to this isolate.

Arakta, Kabuli canoor, P23, Bhagwa, Kabuli, Muscat, Shirin anar are recorded highly susceptible reaction against isolate Aa2421 with PDI ranging from 53.33 to 73.33 per cent whereas two germplasms namely KRS and Yercaud local were susceptible with PDI of 46.67 per cent, while some of the germplasms Mridula, P16, P13, Super bhagwa, Jyoti, GKVR, Muscat New and Kabuli Yellow showed moderately resistant reaction with PDI recorded ranged from 26.67 to 40.00 per cent. None of the germplasms were resistant against this isolate

In response to isolate Aa2523 among the Highly susceptible genotypes group includes the genotypes viz., Mridula, Arakta, P23, Yercaud local, Shirin anar, Kabuli Yellow, Muscat, Kabuli canoor 53.33 to 66.67 per cent PDI. The susceptible group includes the genotypes KRS, P13, P16, Bhagwa, Super bhagwa, Jyoti GKVR and Muscat New. Only one genotype Kasuri shows moderately resistant reaction with PDI of 33.33 per cent.

KRS, Mridula, Arakta, Bhagwa, P13, Kabuli, Muscat, Muscat New, Kasuri, Kabuli canoor genotypes were placed in highly susceptible group in response with isolate Aa1726. P23, Yercaud local and Shirin anar are included under susceptible group. Super bhagwa, P16, Jyoti GKVR and Kabuli Yellow were included under Moderately Resistant group.

In response to the isolate Aa1728, the germplasms P16 and Arakta showed highly susceptible reaction and germplasms Muscat New, Kasuri, Bhagwa, Shirin anar, Super bhagwa, Kabuli canoor, and Muscat included under susceptible reaction group. Remaining genotypes P23, P16, Mridula, KRS, Kabuli, P13, Jyoti GKVR, Yercaud local and Kabuli Yellow show moderately resistance while Muscat alone shows resistant reaction. 
The pathogen used virulence factors such as mycotoxins (oxalic acid, malformin A and malformin C) which helped in disease development (Anderegg et al., 1976) ${ }^{[3]}$. Archana (2012) [4] also observed most of the genotypes exhibited susceptible (Grade 4) to highly susceptible (Grade 5) reacrtion. Genotypes Arakta, Jyothi, Kesar, Kabul, Gul-eshah, Domain and Bedana suri (the popular cultivar among pomegranate growers) were found to be highly susceptible with a PDI ranging between 56.00 to 70.02 per cent. Among the susceptible genotypes viz., A.K. Anar, Achook Dana, Agah, Alah, Bedana sedana, Dorsata malas, Jalore seedless, Lupania and Siah shirin recorded a PDI range of 29.02 to 45.00 per cent.
The genotype Yercaud was to be moderately susceptible (Grade 3) which recorded a PDI of 23.00 per cent.

The similar findings revealed by the author Adesh Kumar et al. (2017) ${ }^{[2]}$ observed that all five isolates A. alternata namely AL14, AL15, AL20, AL21 and AL22 were highly virulent on almost all the pomegranate cultivars. Two cultivars viz. Bhagwa and Mridula were found to be most susceptible as 45.45 per cent isolates were found to be highly virulent on them.

Less susceptibility might be happened due to the highest concentration of antioxidant enzymes in the studied pomegranate cultivars (Arfaoui, et al., 2007; Santigo, et al., 2009; Pal, et al. 2011; Parihar, et al., 2012) ${ }^{[5,10,8,9]}$.

Table 3: Screening of pomegranate germplasms against the isolates of A. alternate

\begin{tabular}{|c|c|c|c|c|c|c|c|}
\hline & \multicolumn{7}{|c|}{ Per cent Disease Index (PDI) } \\
\hline Germplasms & Aa 361 & Aa 2514 & Aa 356 & Aa2421 & Aa 2523 & Aa1726 & Aa 1728 \\
\hline KRS & 46.67 & 40.00 & 26.67 & 46.67 & 46.67 & 73.33 & 33.33 \\
\hline Mridula & 66.67 & 46.67 & 26.67 & 40.00 & 60.00 & 60.00 & 26.67 \\
\hline Arakta & 60.00 & 60.00 & 46.67 & 53.33 & 66.67 & 73.33 & 53.33 \\
\hline P13 & 40.00 & 46.67 & 20.00 & 40.00 & 40.00 & 60.00 & 26.67 \\
\hline P16 & 26.67 & 53.33 & 26.67 & 26.67 & 40.00 & 26.67 & 53.33 \\
\hline P23 & 46.67 & 66.67 & 26.67 & 60.00 & 53.33 & 46.67 & 26.67 \\
\hline Yercaud local & 33.33 & 40.00 & 26.67 & 46.67 & 53.33 & 46.67 & 26.67 \\
\hline Bhagwa & 40.00 & 46.67 & 33.33 & 60.00 & 46.67 & 53.33 & 46.67 \\
\hline Shirin anar & 40.00 & 33.33 & 20.00 & 60.00 & 60.00 & 46.67 & 26.67 \\
\hline Super bhagwa & 40.00 & 46.67 & 20.00 & 40.00 & 40.00 & 33.33 & 46.67 \\
\hline Jyoti GKVR & 26.67 & 40.00 & 26.67 & 33.33 & 53.33 & 40.00 & 26.67 \\
\hline Kabuli Yellow & 40.00 & 60.00 & 26.67 & 26.67 & 66.67 & 33.33 & 33.33 \\
\hline Kabuli & 53.33 & 53.33 & 40.00 & 60.00 & 60.00 & 66.67 & 26.67 \\
\hline Muscat & 26.67 & 40.00 & 26.67 & 53.33 & 53.33 & 60.00 & 26.67 \\
\hline Muscat New & 46.67 & 60.00 & 26.67 & 40.00 & 46.67 & 73.33 & 46.67 \\
\hline Kasuri & 26.67 & 53.33 & 20.00 & 20.00 & 33.33 & 53.33 & 46.67 \\
\hline Kabuli canoor & 60.00 & 66.67 & 40.00 & 73.33 & 66.67 & 60.00 & 46.67 \\
\hline
\end{tabular}

Table 4: Reactions of different Pomegranate germplasms against the different isolates of A. alternate

\begin{tabular}{|c|c|c|c|c|c|c|c|}
\hline \multirow[b]{2}{*}{ Germplasms } & \multicolumn{7}{|c|}{ Reactions of different germplasms against the isolates } \\
\hline & Aa361 & Aa2514 & Aa 356 & Aa2421 & Aa 2523 & Aa1726 & Aa 1728 \\
\hline KRS & $\mathrm{S}$ & $\mathrm{MR}$ & MR & $\mathrm{S}$ & $\mathrm{S}$ & HS & $\mathrm{S}$ \\
\hline Mridula & HS & $\mathrm{S}$ & MR & MR & HS & $\mathrm{HS}$ & MR \\
\hline Arakta & HS & HS & $\mathrm{S}$ & HS & HS & $\mathrm{HS}$ & $\mathrm{HS}$ \\
\hline P13 & $\mathrm{S}$ & $\mathrm{S}$ & $\mathrm{R}$ & MR & $\mathrm{S}$ & $\mathrm{HS}$ & MR \\
\hline P16 & MR & $\mathrm{S}$ & MR & MR & $\mathrm{S}$ & MR & $\mathrm{HS}$ \\
\hline P23 & $\mathrm{S}$ & $\mathrm{HS}$ & MR & $\mathrm{HS}$ & $\mathrm{HS}$ & $\mathrm{S}$ & MR \\
\hline Yercaud local & $\mathrm{S}$ & MR & MR & $\mathrm{S}$ & $\mathrm{HS}$ & $\mathrm{S}$ & MR \\
\hline Bhagwa & $\mathrm{S}$ & $\mathrm{S}$ & MR & $\mathrm{HS}$ & $\mathrm{S}$ & $\mathrm{HS}$ & $\mathrm{S}$ \\
\hline Shirin anar & $\mathrm{S}$ & MR & $\mathrm{R}$ & MR & MR & $\mathrm{S}$ & MR \\
\hline Super bhagwa & $\mathrm{S}$ & $\mathrm{S}$ & $\mathrm{R}$ & MR & $\mathrm{S}$ & MR & $\mathrm{S}$ \\
\hline Jyoti GKVR & MR & $\mathrm{S}$ & MR & MR & $\mathrm{S}$ & MR & MR \\
\hline Kabuli Yellow & $\mathrm{S}$ & $\mathrm{HS}$ & MR & MR & $\mathrm{HS}$ & MR & MR \\
\hline Kabuli & $\mathrm{HS}$ & $\mathrm{HS}$ & $\mathrm{S}$ & $\mathrm{HS}$ & HS & $\mathrm{HS}$ & MR \\
\hline Muscat & MR & MR & MR & $\mathrm{HS}$ & $\mathrm{HS}$ & $\mathrm{HS}$ & $\mathrm{R}$ \\
\hline Muscat New & $\mathrm{S}$ & $\mathrm{HS}$ & MR & MR & $\mathrm{S}$ & $\mathrm{HS}$ & $\mathrm{S}$ \\
\hline Kasuri & MR & $\mathrm{S}$ & $\mathrm{R}$ & $\mathrm{R}$ & MR & $\mathrm{S}$ & $\mathrm{S}$ \\
\hline Kabuli canoor & HS & $\mathrm{HS}$ & $\mathrm{S}$ & $\mathrm{HS}$ & $\mathrm{HS}$ & HS & $\mathrm{S}$ \\
\hline
\end{tabular}

**I-Immune, HR-Highly Resistant, R-Resistant, MR-Moderately Resistant, S-Susceptible, HS-Highly susceptible

\section{References}

1. Anonymous, Indiastat 2016-17, 2017.

2. Adesh K, Tanjeet SC, Mandeep SH, Harminder K, Roomi R. Studies of alternaria black spot disease of pomegranate caused by Alternaria alternata in Punjab. 2017. Journal of Applied and Natural Science. 2017; 9(1):156-161.

3. Anderegg RJ, Biemann K, Buechi G, Cushman M, Malformin C. A new metabolite of Aspergillus niger. J. American Chemi. Soc. 1976; 98:3365-70.
4. Archana S, Naina S. Effect of carbon (carbohydrate) and nitrogen (protein) sources in vitro growth of Alternaria solani. J. Env. Bio-Sci., 2012; 26(1):71-74

5. Arfaoui A, Hadram EIA, Mabrouk Y, Sifi B, Boudabous A, Hadrami EII, Daayy F, Cherif M. Treatment of chickpea with Rhizobium isolates enhances the expression of phenylpropanoid defense related genes in response to infection by Fusarium oxysporum f sp. ciceris. Plant Physiol. Biochem. 2007; 45:470-79. 
6. Devananthan M, Ramanujam K. Evaluation of fungicides for the management of early blight of tomato caused by Alternaria solani. Madras Agricultural Journal 1995; 82:228-229.

7. Mckinney HH. Influence of soil temperature and moisture on infection of wheat seedlings by Helminthosporiumsativium. Journal of Agricultural Research, 1923; 26:195-217

8. Pal TK, Bhattacharaya S, Chakraborty K. Induction of systemic resistance in rice by leaf extract of Cymbopogan citrus and Ocimum sanctum against sheath blight disease. Arch. Appl. Sci. Res. 2011; 3:392-400.

9. Parihar PS, Prakash O, Punetha H. Investigation on defensive enzymes activity of Brassica juncea genotypes during pathogenesis of Alternaria blight. Natl. Sci. 2012; 10:63-68.

10. Santigo R, De Armas R, Legaz M, Vicente C. Changes in phenolic acids content, phenylalanine ammonia lyase and peroxidase activities in sugarcane leaves induced by elicitors isolated from Xanthomonas albilineans. Aust. J. Plant Pathol. 2009; 38:357-65.

11. Yarwood CE. Detached leaf culture. Botanical Review, 1946; 12:51-56. 